\title{
Dental Students' Learning Experiences and Preferences Regarding Orofacial Pain: A Cross-Sectional Study
}

\author{
Sorin T. Teich, DMD, MBA; Aurelio A. Alonso, DDS, MS, PhD; Lisa Lang, DDS, MS, MBA; \\ Masahiro Heima, DDS, PhD
}

Abstract: Pain is a global health problem, the effects of which range from diminished quality of life to pain management costs and loss of work and productivity. Pain in the head and neck region is defined as a separate entity: orofacial pain (OFP). However, some graduates from dental schools have reported feeling less competent in their ability to diagnose OFP than in other areas of dentistry. The aims of this study were to assess how students at one U.S. dental school had learned about OFP and to identify the teaching methods and venues they would like to see enhanced in the school's OFP curriculum. A cross-sectional four-question survey was administered to 140 dental students in their third and fourth years; the survey had a response rate of 53\%. Most students reported having gained their OFP knowledge mainly in dental school, and $91.9 \%$ selected didactic courses as the main teaching method in which they had learned about this topic. Clinical education was the main teaching venue these students said they would like to see enhanced in order to gain more knowledge in most forms of OFP; this result aligned with their learning preferences in general. These findings may help dental schools design their OFP curricula to take account of students' preferences as well as practical limitations regarding availability of clinical experiences.

Dr. Teich is Associate Professor and Associate Dean of Clinical Operations, Department of Comprehensive Care, School of Dental Medicine, Case Western Reserve University; Dr. Alonso is Assistant Professor, Department of Comprehensive Care, School of Dental Medicine, Case Western Reserve University; Dr. Lang is Associate Professor and Chair, Department of Comprehensive Care, School of Dental Medicine, Case Western Reserve University; and Dr. Heima is Assistant Professor, Department of Pediatric Dentistry, School of Dental Medicine, Case Western Reserve University. Direct correspondence to Dr. Sorin T. Teich, Department of Comprehensive Care, School of Dental Medicine, Case Western Reserve University, 2124 Cornell Rd., Cleveland, OH 44106; 216-368-6161; sorin@case.edu.

Keywords: dental education, clinical education, clinical skills, orofacial pain, teaching methods, temporomandibular disorders

Submitted for publication 12/15/14; accepted 4/7/15

$\mathrm{P}$ ain is a global health problem, the effects of which range from pain management costs, often performed by an interdisciplinary team, to loss of work and productivity to diminished quality of life. A recent systematic review determined that, in general, chronic pain has an average prevalence of $22 \%$ in adults, with $7 \%$ presenting with severe pain. ${ }^{1}$ Pain in the head and neck region is defined as a separate entity: orofacial pain (OFP) ${ }^{2-5}$ There is considerable variation in the reported prevalence of OFP, with the median reported as $13 \%$ (min $1 \%$, max $48 \%)$. ${ }^{4}$ Some graduates of dental schools have reported feeling less competent in their ability to diagnose OFP compared to other fields of dentistry. ${ }^{6,7}$ This perception has also been observed in general medicine, in which both academic and community physicians have reported perceived lack of competence in pain management. ${ }^{8}$ Although pain has been reported as the most common reason for a patient to consult a general practitioner, only $3-4 \%$ of medical schools in the United States and 1\% in Europe dedicate a specific part of their curricula to pain. ${ }^{9-11}$
Temporomandibular disorders (TMD) often involve pain, but a study of TMD education in predoctoral U.S. and Canadian dental curricula reported in 2007 that many institutions were not providing sufficient TMD instruction, with only three schools out of 53 describing their curricula as "ideal."12 For these reasons, the authors of that study expressed concern that patients suffering from TMD and OFP in North America may not be receiving appropriate care by their primary providers. Similar conclusions were drawn in a study showing that the level of knowledge about pain was consistently low among dental students. ${ }^{13}$ In a previous article,${ }^{14}$ we pointed out that although the Commission on Dental Accreditation (CODA) has approved accreditation standards in OFP for advanced general education programs, ${ }^{15}$ these standards do not apply to the predoctoral curriculum. Searching the CODA predoctoral standards for the word "pain" elicited only one result: Standard 2-23.e., which includes no specific mention of TMD or OFP. ${ }^{16}$ This situation is not unique to U.S. dental education: it has also been identified as a gap in 
Europe,${ }^{17}$ where curriculum guidelines for teaching OFP in undergraduate programs exist. ${ }^{18}$ These findings underscore the ongoing need for developing new curricula and strengthening predoctoral dental education in OFP and TMD. ${ }^{8,12,19}$

At Case Western Reserve University (CWRU) School of Dental Medicine, the four-year predoctoral curriculum provides exposure to a variety of OFP subsets: TMD-associated pain, primary headache disorders, neuropathic pain disorders, intraoral pain disorders, and psychogenic pain. ${ }^{5}$ Psychogenic pain is a diagnosis that is appropriate when organic causes are absent $t^{20}$ or when psychological factors are judged to play a significant role in the onset, severity, exacerbation, or maintenance of pain. ${ }^{21}$ The third-year course dedicated specifically to OFP includes 19 hours of lectures and lab in addition to pain-related material taught in other courses. ${ }^{14}$ This allocation is greater than the median number of hours dedicated to studying pain in medical schools in the United States (median $=9$ hours) and Europe (median=12 hours) and in the same range as in Canada (median=19.5 hours). ${ }^{9,11}$ Nevertheless, we hope to continue to improve our students' OFP education and encourage other dental schools to do so. The aims of this study were to assess how our students had learned about OFP and to identify the teaching methods and venues they would like to see enhanced in the school's OFP curriculum.

\section{Materials and Methods}

The research protocol for this study was approved by CWRU's Institutional Review Board. A cross-sectional four-question survey we designed using Tailored Design Method $^{22}$ principles was distributed in March 2013 to all 140 third- and fourthyear dental students via the CWRU email list. Data were collected using SurveyMonkey. Three emails were sent to the students as reminders to complete the survey. The first email contained information about the survey and the link providing access to it. A second email was sent two weeks later, followed by a third and last email reminder two weeks later.

The first question asked where the students had gained their knowledge in each of five areas of OFP (TMD-related pain, primary headaches, neuropathic pain, intraoral pain, and psychogenic pain). Answer options were as follows: undergraduate studies before dental school, postgraduate studies before dental school, dental school, continuing education, professional/scientific meetings, other. Respondents were allowed to choose all that applied. The second question asked in which teaching methods and venues students had received OFP education during dental school. Answer options for this question were as follows: didactic courses, problem-based learning (PBL), team-based learning (TBL), seminars/journal clubs, clinical observation only, clinical examination of orofacial pain patients, clinical diagnosis of orofacial pain patients, clinical treatment of orofacial pain patients, other. Respondents were allowed to choose all that applied.

The third question asked which teaching methods or venues students would like to see enhanced to increase their knowledge in each category of OFP. Answer options were as follows: didactic courses, PBL, TBL, clinical experience, seminar/journal club, other, I would not enhance anything in the dental school curriculum. Respondents were allowed to choose all that applied. The final question asked about the students' preferred methods of learning in general (i.e., not specifically related to OFP). Respondents were asked to indicate their preference on a scale from $1=$ least preferred to $5=$ most preferred regarding five teaching methods/venues: didactic courses, PBL, TBL, seminars/journal clubs, and clinical activity. ${ }^{23}$

IBM SPSS Version 21 (IBM Corp., Armonk, NY, USA) was used for statistical analysis. Statistical significance for all analyses was set at $p<0.05$. For questions 1-3, two by two cross tabulations using Pearson's chi-square or Fisher's exact test followed by Bonferroni correction were performed to determine if answers provided by the third- and fourth-year students could be combined for analysis. For question 4, the General Linear Model (GLM) was applied as follows: first, the Mauchly's Test of Sphericity was conducted to test whether variances of the differences between all possible pairs of thirdand fourth-year students and preferred methods of gaining knowledge could be assumed equal; this was followed by the Huynh-Feldt and the lower-bound correction tests. Following calculation of estimated means and corresponding 95\% confidence intervals, a pairwise comparison of the results was performed.

\section{Results}

Out of 140 students who received the survey, 74 completed it in its entirety ( 36 third-year and 38 fourth-year students), for a $53 \%$ response rate. This response rate was in the expected range for edu- 
cational research. ${ }^{24}$ Analysis of data from the first three questions showed no statistically significant differences in the proportion distributions of answers provided by third- and fourth-year students, allowing their answers to be combined.

On the first question, most students reported having gained their knowledge in all five OFP categories mainly in dental school. The percentages for each area were as follows: intraoral pain and TMDrelated pain, both $94.6 \%$; neuropathic pain, $85.1 \%$; primary headaches, $78.4 \%$; and psychogenic pain, $54.1 \%$ (Table 1). Only a few students reported having gained some knowledge in OFP categories outside the dental school. On the second question, $91.9 \%$ of the respondents said that in dental school they had learned about OFP in didactic courses, followed by clinical examination of OFP patients (31.1\%), clinical diagnosis of OFP patients (23\%), clinical treatment of OFP patients $(18.9 \%)$, and clinical observation $(10.8 \%)$ (Table 2). PBL was reported by the same percentage of students as clinical observation $(10.8 \%)$, followed by TBL $(6.8 \%)$ and seminars $(1.4 \%)$.

Answers to the third question revealed that clinical experience was the main teaching venue that students would like to see enhanced in order to gain more knowledge in most OFP categories (Table 3). The field of psychogenic pain was the single exception, with students indicating the need to enhance mostly didactic training $(41.9 \%)$ in that area, followed by clinical experience (36.5\%). For all other OFP categories, didactic education was ranked second. PBL was ranked third for all OFP categories except for primary headache, on which it was ranked fourth after TBL (13.5\% and $16.2 \%$, respectively).

To explore if the third- and fourth-year students' answers to the fourth question could be combined for statistical analysis, the Mauchly's Test of Sphericity was conducted. The test rejected the null assumption that variances of the differences between all possible pairs of students and preferred methods of gathering knowledge could be assumed equal $(\chi 2=56.661$, $\mathrm{df}=9, \mathrm{p}<0.001)$. Following the determination that the sphericity null assumption was violated, the results were analyzed with correction tests to determine if the differences were related to the respondents (thirdyear versus fourth-year) or to the different preferred learning methods. The Huynh-Feldt correction test showed that the two groups were not different in the way they responded $(\mathrm{F}=0.457, \mathrm{p}=0.718)$. The lowerbound correction test showed significant differences in responses related to the preferred learning methods $(\mathrm{F}=70.044, \mathrm{p}<0.001)$.

The determination that there was no significant difference between the two cohorts' data allowed combining the answers to this question provided by all respondents. The results showed that the students' preferred method of gaining knowledge was clinical activity $(\mathrm{M}=4.78, \mathrm{SD}=0.476)$, followed by didactic courses $(\mathrm{M}=3.22, \mathrm{SD}=1.296)$, seminars/journal clubs $(\mathrm{M}=2.86, \mathrm{SD}=1.186), \mathrm{PBL}(\mathrm{M}=2.43, \mathrm{SD}=1.183)$, and lastly TBL $(\mathrm{M}=2.19, \mathrm{SD}=1.069)$ (Table 4). To explore which of these means differed statistically, the estimated means for differences between the results and corresponding $95 \%$ confidence intervals were calculated (results not shown), followed by pairwise comparisons with the least significant differences (LSD) test (Table 5). Statistically significant differences between most methods of gaining knowledge were evident, with clinical activities being the students' preferred method over any other. Didactic courses were preferred over PBL and TBL but were no different from seminars/journal clubs. No statistically significant difference was observed between PBL and TBL.

Table 1. Where/when students reported having gained their orofacial pain knowledge in five areas, by number and percentage of total respondents $(\mathrm{N}=74)$

\begin{tabular}{lccccc} 
& $\begin{array}{c}\text { TMD-Related } \\
\text { Pain }\end{array}$ & $\begin{array}{c}\text { Primary } \\
\text { Headaches }\end{array}$ & $\begin{array}{c}\text { Neuropathic } \\
\text { Pain }\end{array}$ & $\begin{array}{c}\text { Intraoral } \\
\text { Pain }\end{array}$ & $\begin{array}{c}\text { Psychogenic } \\
\text { Pain }\end{array}$ \\
\hline Undergraduate studies before dental school & $2(2.7 \%)$ & $7(9.5 \%)$ & $3(4.1 \%)$ & $3(4.1 \%)$ & $4(5.4 \%)$ \\
Postgraduate studies before dental school & 0 & $1(1.4 \%)$ & $1(1.4 \%)$ & $1(1.4 \%)$ & $2(2.7 \%)$ \\
Dental school & $70(94.6 \%)$ & $58(78.4 \%)$ & $63(85.1 \%)$ & $70(94.6 \%)$ & $40(54.1 \%)$ \\
Continuing education & $5(6.8 \%)$ & $2(2.7 \%)$ & $2(2.7 \%)$ & $5(6.8 \%)$ & $2(2.7 \%)$ \\
Professional/scientific meetings & $2(2.7 \%)$ & $1(1.4 \%)$ & $1(1.4 \%)$ & $5(6.8 \%)$ & $2(2.7 \%)$ \\
Other & $7(9.5 \%)$ & $8(10.8 \%)$ & 0 & 0 & $1(1.4 \%)$
\end{tabular}

Note: Respondents could choose all that applied. 


\section{Discussion}

Although educators have been trying to develop OFP curricula for predoctoral and postdoctoral students, ${ }^{12,25-28}$ this is the first study to provide information related to predoctoral dental students' learning preferences in relation to OFP. Dental education should be student-centered ${ }^{29}$ therefore, students' learning preferences need to be taken into account when curricula are designed.

Our results showed that these students' OFP education had mostly occurred in dental school (Table 1). In the dental school, the most prevalent methodology in which they learned about OFP was didactic lectures (reported by $91.9 \%$ ), followed by clinical experience that included examination of a patient (31.1\%). Overall, $83.8 \%$ of these students
Table 2. How students reported having been educated about orofacial pain in dental school, by number and percentage of total respondents $(\mathrm{N}=74)$

Method/Venue

Number (Percentage)

\begin{tabular}{lc}
\hline Didactic courses & $68(91.9 \%)$ \\
Problem-based learning & $8(10.8 \%)$ \\
Team-based learning & $5(6.8 \%)$ \\
Seminars/journal clubs & $1(1.4 \%)$ \\
Clinical observation only & $8(10.8 \%)$ \\
$\begin{array}{l}\text { Clinical examination of orofacial pain } \\
\text { patient }\end{array}$ & $23(31.1 \%)$ \\
$\begin{array}{l}\text { Clinical diagnosis of orofacial pain } \\
\text { patient }\end{array}$ & $17(23.0 \%)$ \\
$\begin{array}{l}\text { Clinical treatment of orofacial pain } \\
\text { patient }\end{array}$ & $14(18.9 \%)$ \\
Other & $1(1.4 \%)$
\end{tabular}

Note: Respondents could choose all that applied.

Table 3. Teaching methods/venues that students wanted to see enhanced to increase their knowledge in five areas of orofacial pain, by number and percentage of total respondents $(\mathrm{N}=74)$

\begin{tabular}{|c|c|c|c|c|c|}
\hline Method/Venue & $\begin{array}{c}\text { TMD-Related } \\
\text { Pain }\end{array}$ & $\begin{array}{l}\text { Primary } \\
\text { Headaches }\end{array}$ & $\begin{array}{c}\text { Neuropathic } \\
\text { Pain }\end{array}$ & $\begin{array}{l}\text { Intraoral } \\
\text { Pain }\end{array}$ & $\begin{array}{l}\text { Psychogenic } \\
\text { Pain }\end{array}$ \\
\hline Didactic courses & $27(36.5 \%)$ & $41(55.4 \%)$ & $39(52.7 \%)$ & $33(44.6 \%)$ & $31(41.9 \%)$ \\
\hline Problem-based learning & $16(21.6 \%)$ & $10(13.5 \%)$ & $12(16.2 \%)$ & $17(23.0 \%)$ & $14(18.9 \%)$ \\
\hline Team-based learning & $9(12.2 \%)$ & $12(16.2 \%)$ & $9(12.2 \%)$ & $8(10.8 \%)$ & $7(9.5 \%)$ \\
\hline Clinical experience & $66(89.2 \%)$ & $43(58.1 \%)$ & $46(62.2 \%)$ & $56(75.7 \%)$ & $27(36.5 \%)$ \\
\hline Seminars/journal clubs & $12(16.2 \%)$ & $9(12.2 \%)$ & 0 & $4(5.4 \%)$ & $3(4.1 \%)$ \\
\hline Other & $5(6.8 \%)$ & 0 & 0 & 0 & $1(1.4 \%)$ \\
\hline I would not enhance anything & $2(2.7 \%)$ & $5(5.8 \%)$ & $7(9.5 \%)$ & $7(9.5 \%)$ & $4(5.4 \%)$ \\
\hline
\end{tabular}

Table 4. Students' preferred methods of learning in general $(\mathrm{N}=74)$

\begin{tabular}{lccccc} 
& $\begin{array}{c}\text { Didactic } \\
\text { Courses }\end{array}$ & $\begin{array}{c}\text { Problem-Based } \\
\text { Learning }\end{array}$ & $\begin{array}{c}\text { Team-Based } \\
\text { Learning }\end{array}$ & $\begin{array}{c}\text { Seminars/Journal } \\
\text { Clubs }\end{array}$ & $\begin{array}{c}\text { Clinical } \\
\text { Activity }\end{array}$ \\
\hline Mean & 3.22 & 2.43 & 2.19 & 2.86 & 4.78 \\
Std. Deviation & 1.296 & 1.183 & 1.069 & 1.186 & 0.476
\end{tabular}

Note: Respondents ranked each item on a scale of $1-5$ on which $1=$ least preferred and $5=$ most preferred.

Table 5. Pairwise comparisons for students' preferred method of learning $(N=74)$

\begin{tabular}{lccccc} 
& $\begin{array}{c}\text { Didactic } \\
\text { Courses }\end{array}$ & $\begin{array}{c}\text { Problem-Based } \\
\text { Learning }\end{array}$ & $\begin{array}{c}\text { Team-Based } \\
\text { Learning }\end{array}$ & $\begin{array}{c}\text { Seminars/Journal } \\
\text { Clubs }\end{array}$ & $\begin{array}{c}\text { Clinical } \\
\text { Activity }\end{array}$ \\
\hline Didactic courses & - & $0.009^{*}$ & $<0.001^{*}$ & 0.744 & $<0.001^{*}$ \\
Problem-based learning & $0.009^{*}$ & - & 0.352 & 0.257 & $<0.001^{*}$ \\
Team-based learning & $<0.001^{*}$ & 0.352 & - & $0.003^{*}$ & $<0.001^{*}$ \\
Seminars/journal clubs & 0.744 & 0.257 & $0.003^{*}$ & - & $<0.001^{*}$ \\
Clinical activity & $<0.001^{*}$ & $<0.001^{*}$ & $<0.001^{*}$ & $<0.001^{*}$ & -
\end{tabular}

*Statistically significance at $\mathrm{p}<0.05$ based on cross-tabulations of mean differences 
reported having had some type of clinical experience ranging from observation to treatment (Table 2).

These students wanted enhanced clinical experience (Table 3) mainly in relation to TMD-related pain (clinical $89.2 \%$, didactic $36.5 \%$ ) and intraoral pain (clinical $75.7 \%$, didactic $44.6 \%$ ). In the area of neuropathic pain, they also reported wanting more clinical experience $(62.2 \%)$, closely followed by didactic instruction $(52.7 \%)$. The same trend was observed regarding primary headaches: their desire for enhanced clinical experience $(58.1 \%)$ in that area was nearly similar to didactic lectures $(55.4 \%)$. It is interesting to note that, in the area of psychogenic pain, the students reported wanting more didactic lectures $(41.9 \%)$ compared to clinical experience (36.5\%), indicating they felt the need for more theoretical information before being exposed to clinical cases. These percentages are consistent with our previously published data showing that CWRU students felt less knowledgeable regarding psychogenic pain than other categories of OFP. ${ }^{14}$ In that study, students reported a significant perceived need for more knowledge in all OFP categories; on a scale of $1=$ low to $5=$ high, fourth-year student responses ranged from an average of $3.28(\mathrm{SD}=0.91)$ for intraoral pain to $4.24(\mathrm{SD}=0.56)$ for primary headaches.

Since 2007, students at CWRU have participated in active learning in a small group format throughout the curriculum..$^{30}$ Although the PBL and TBL sessions receive consistently positive reviews, the results from this study indicated the students' general preference for gaining knowledge through clinical activity $(\mathrm{M}=4.78, \mathrm{SD}=0.476)$ over other teaching methods $(\mathrm{p}<0.001)$. We acknowledge that this preference would surely vary depending on the contents of the learning experience and may simply reflect the value these third- and fourth-year students placed on the clinical education they were currently receiving in those years prior to graduation and entering practice. Didactic lectures were ranked next highest with a mean of $3.22(\mathrm{SD}=1.296)$; that score was significantly higher than their scores for PBL $(p=0.009)$ and TBL $(p<0.001)$ but similar to the seminars/journal clubs score $(p=0.744)$. There was no statistical difference between students' preference for TBL and PBL $(p=0.352)$. These results were consistent with the responses about which teaching methods/venues students would like to see enhanced regarding TMD, intraoral pain, and neuropathic pain (Table 3). The relationship was less clear when clinical experience is compared to didactic lectures in the areas of primary headaches and psychogenic pain. It is evident, however, that students ranked PBL and TBL methods for all OFP categories far behind clinical experiences and didactic lectures. These results were contrary to those of Murphy et al., who reported that the dental students in their study preferred more visual learning (lectures) than kinesthetic learning (clinical experience). ${ }^{31}$

It is generally agreed in dental education that no single educational method is superior to others in all situations. ${ }^{29}$ Although some advocate a transition to PBL methodologies, ${ }^{32}$ others have found limited evidence that PBL is superior to traditional methods..$^{29,33-35}$ Differences have also been seen in studies with a specific focus on OFP curricula. ${ }^{36-38}$ Traditionally, OFP has been taught through lectures, seminars, case studies, and labs. ${ }^{9,39}$ Recently, educators have suggested a change to mixed formats, adding methods such as e-learning, ${ }^{40}$ standardized patients, ${ }^{41,42}$ elective clinical courses,${ }^{43}$ and smallgroup learning or PBL. ${ }^{41,44}$ Despite one report that students who experienced a PBL curriculum felt more prepared to manage chronic pain than students trained in a traditional way, ${ }^{37} \mathrm{PBL}$ is used in only $41.9 \%$ of OFP curricula in the United Kingdom. ${ }^{9}$ The effectiveness of mixed methods in teaching OFP is still to be assessed..$^{44}$

One methodological limitation of this study is that the questionnaire was not pre-validated before being administered. In addition, because the questionnaire was not mandatory, it is possible that students who responded pre-selected themselves, potentially creating a selection bias. However, the fact that we used two student classes and found no difference in distribution of the answers is a strong indication that self-selection bias did not occur. We also recognize that the surveyed population may not be representative of all students in the United States or North America. However, these results may catalyze similar research projects in other schools around a variety of educational topics. Future surveys on this topic might consider changes in the questions. The questions in this study addressed only students' knowledge, whereas it would be useful to ask about their perceived skills as well, especially considering their expressed desire for additional clinical experience. Also, on question two, since the teaching methods and venues in the current OFP curriculum can be empirically determined, it might be useful to ask students from which they learned the most, rather than only the ones they experienced. Those responses could be helpful in evaluating the balance of teaching methods/venues used. 


\section{Conclusion}

In this study, third- and fourth-year dental students showed a significant preference for learning about OFP through clinical experience and didactic lectures. This result was supported by their wish to enhance the OFP curriculum with clinical and didactic lecture experiences rather than PBL. When developing OFP curricula, dental schools should consider both students' preferences and practical limitations in availability of clinical experiences in OFP. Additions may include case presentations by faculty, elective mini-courses, clinical observations, clinical rounds, or objective structured clinical examinations (OSCEs). Further studies are needed to investigate if curricula that use educational methodologies preferred by students have better educational outcomes than programs that promote active learning such as TBL and PBL.

\section{REFERENCES}

1. Moore RA, Derry S, Taylor RS, et al. The costs and consequences of adequately managed chronic non-cancer pain and chronic neuropathic pain. Pain Pract 2014;14(1): 79-94.

2. Koratkar HPJ. Atypical odontalgia: a review. Northwest Dent 2008;87(1):37-8,62.

3. Hardt J, Jacobsen C, Goldberg J, et al. Prevalence of chronic pain in a representative sample in the United States. Pain Med 2008;9(7):803-12.

4. Macfarlane TV, Glenny AM, Worthington HV. Systematic review of population-based epidemiological studies of orofacial pain. J Dent 2001;29(7):451-67.

5. de Leeuw R, Klasser GD. Orofacial pain: guidelines for assessment, diagnosis, and management. 5th ed. Hanover Park, IL: Quintessence, 2013.

6. Greenwood L, Lewis D, Burgess R. How competent do our graduates feel? J Dent Educ 1998;62(4):307-13.

7. Holmes D, Diaz-Arnold A, Williams V. Alumni selfperception of competence at time of dental school graduation. J Dent Educ 1997;61(6):465-72.

8. Tauben DJ, Loeser JD. Pain education at the University of Washington School of Medicine. J Pain 2013;14(5):431-7.

9. Briggs M, Carr E, Whittaker M. Survey of undergraduate pain curricula for health care professionals in the United Kingdom: a short report. London: British Pain Society, 2009.

10. Vadivelu N, Mitra S, Hines R, et al. Acute pain in undergraduate medical education: an unfinished chapter! Pain Pract 2012;12(8):663-71.

11. Mezei L, Murinson BB. Pain education in North American medical schools. J Pain 2011;12(12):1199-208.

12. Klasser GD, Greene CS. Predoctoral teaching of temporomandibular disorders: a survey of U.S. and Canadian dental schools. J Am Dent Assoc 2007;138(2):231-7.
13. Borromeo GL, Trinca J. Understanding of basic concepts of orofacial pain among dental students and a cohort of general dentists. Pain Med 2012;13(5):631-9.

14. Alonso AA, Heima M, Lang LA, Teich ST. Dental students' perceived level of competence in orofacial pain. J Dent Educ 2014;78(10):1379-87.

15. Commission on Dental Accreditation. Accreditation standards for advanced education general dentistry education programs in orofacial pain. Chicago: American Dental Association, 2009.

16. Commission on Dental Accreditation. Accreditation standards for dental education programs. 2013. At: www.ada. org/sections/educationAndCareers/pdfs/predoc_2013.pdf. Accessed 15 Dec. 2014.

17. Steenks MH. The gap between dental education and clinical treatment in temporomandibular disorders and orofacial pain. J Oral Rehabil 2007;34(7):475-7.

18. Nilner M. Curriculum guidelines for orofacial pain and temporomandibular disorders. Eur J Dent Educ 2001; 5(3):136-8

19. Tegelberg $\AA$, Wenneberg B, List T. General practice dentists' knowledge of temporomandibular disorders in children and adolescents. Eur J Dent Educ 2007;11(4):216-21.

20. Scully C, Felix D. Oral medicine: update for the dental practitioner, orofacial pain. Br Dent J 2006;200(2):75-83.

21. Doleys DM. Pain: dynamics and complexities. New York: Oxford University Press, 2014.

22. Dillman DA. Mail and internet surveys: the tailored design method. New York: Wiley, 2000.

23. Likert R. A technique for the measurement of attitudes. Archiv Psychol 1932;22(140):1-55.

24. Porter SR, Whitcomb ME. The impact of lottery incentives on student survey response rates. Res Higher Educ 2003;44(4):389-407.

25. Attanasio R, Mohl ND. Suggested curriculum guidelines for the development of continuing education programs in TMD and orofacial pain. J Craniomandibular Dis 1992;6(2):137-40.

26. Greene CS, Stockstill JW, Clark GT. Predoctoral education for TMD and orofacial pain: a philosophical overview. J Craniomandibular Dis 1992;6(2):111-2.

27. Mohl ND, Attanasio R. The third educational conference to develop the curriculum in temporomandibular disorders and orofacial pain: introduction. J Orofac Pain 2002;16(3):173-5.

28. Stockstill JW. Curriculum outline for adjunctive predoctoral education in TMD and orofacial pain. J Craniomandibular Dis 1992;6(2):117-22.

29. Plasschaert A, Manogue M, Lindh C, et al. Curriculum content, structure, and ECTS for European dental schools. Part II: methods of learning and teaching, assessment procedures, and performance criteria. Eur J Dent Educ 2007;11(3):125-36.

30. Pyle MA, Goldberg JS. Engineering curriculum change at a private midwest school of dental medicine: a faculty innovation. J Dent Educ 2008;72(3):288-98.

31. Murphy RJ, Gray SA, Straja SR, Bogert MC. Student learning preferences and teaching implications. J Dent Educ 2004;68(8):859-66.

32. Nadershahi NA, Bender DJ, Beck L, et al. An overview of case-based and problem-based learning methodologies for dental education. J Dent Educ 2013;77(10):1300-5. 
33. Albanese M. Problem-based learning: why curricula are likely to show little effect on knowledge and clinical skills. Med Educ 2000;34(9):729-38.

34. Hartling L, Spooner C, Tjosvold L, Oswald A. Problembased learning in preclinical medical education: 22 years of outcome research. Med Teach 2010;32(1):28-35.

35. Romito LM, Eckert GJ. Relationship of biomedical science content acquisition performance to students' level of PBL group interaction: are students learning during PBL group? J Dent Educ 2011;75(5):653-64.

36. Alsafi Z, Michelotti A, Ohrbach R, et al. Achieved competence in temporomandibular disorders/orofacial pain: a comparison between two dental schools in Europe. Eur J Dent Educ, forthcoming.

37. Greenwood LF, Townsend GC, Wetherell JD, Mullins GA. Self-perceived competence at graduation: a comparison of dental graduates from the Adelaide PBL curriculum and the Toronto traditional curriculum. Eur J Dent Educ 1999;3(4):153-8.

38. Yiu CK, McGrath C, Bridges S, et al. Graduates' perceived preparedness for dental practice from PBL and traditional curricula. J Dent Educ 2011;75(9):1270-9.
39. Sessle BJ. Integration of basic sciences into the predoctoral curriculum to study temporomandibular disorders and orofacial pain. J Orofac Pain 2002;16(3):181-4.

40. Yanni LM, Priestley JW, Schlesinger JB, et al. Development of a comprehensive e-learning resource in pain management. Pain Med 2009;10(1):95-105.

41. Watt-Watson J, Hunter J, Pennefather P, et al. An integrated undergraduate pain curriculum, based on IASP curricula, for six health science faculties. Pain 2004;110(12): $140-8$

42. Attanasio R. The study of temporomandibular disorders and orofacial pain from the perspective of the predoctoral dental curriculum. J Orofac Pain 2002;16(3):176-80.

43. Gonzalez YM, Mohl ND. Care of patients with temporomandibular disorders: an educational challenge. J Orofac Pain 2002;16(3):200-6.

44. Ivanoff CS, Hottel TL. A four-tier problem-solving scaffold to teach pain management in dental school. J Dent Educ 2013;77(6):723-31. 